\title{
The weight of light*
}

\section{El peso de la luz}

Received: 10 March 2016 | Accepted: 20 June 2016

\section{Sergio Cesare Masin}

University of Padua, Italy

\begin{abstract}
The study explored whether the knowledge of Archimedes' law of the lever can be used to measure subjective intensities. Participants were presented with two achromatic rectangles on a horizontal line-drawn lever, one on the left and one on the right of the fulcrum. The left rectangle had a fixed low luminance. For different combinations of luminance and distance from the fulcrum of the right rectangle, participants were asked to position the left rectangle at a distance from the fulcrum such that the weight of the light emitted by the left rectangle kept the lever horizontal given the weight of the light emitted by the right rectangle. Most of the participants solved the task in accordance with their knowledge of Archimedes' law. This finding is interpreted to imply that the perceived distance of the left rectangle from the fulcrum was proportional to the perceived brightness of the right rectangle. It suggests that people's explicit or implicit knowledge of ratios and proportions in Archimedes' law of the lever, and perhaps in other physical laws, could potentially be used to measure any subjective intensity on a ratio scale.
\end{abstract}

Keywords

Physical laws, psychophysics, Archimedes law, Integration Information Theory

\section{RESUMEN}

Este estudio explora si el conocimiento de las leyes de Arquímedes de las palancas puede ser usado para la medición subjetiva de las intensidades. Se les presentaron a los participantes dos rectángulos en escala de grises, ubicados sobre una palanca dibujada como una línea horizontal, uno a la derecha y uno a la izquierda del fulcro. El rectángulo de la izquierda fue fijado con una iluminación baja. Para las diferentes combinaciones de iluminación y distancia del fulcro se usó el rectángulo de la derecha. Los participantes fueron interrogados sobre la posición y la distancia del rectángulo de la izquierda con respecto al fulcro, tanto como sobre el peso y la luz emitida por el rectángulo de la derecha. La mayoría de los participantes solucionaron la tarea de acuerdo con su conocimiento de las leyes de Arquímedes. Este hallazgo es interpretado como una implicación de que la distancia percibida del rectángulo de la izquierda con respecto al fulcro fue proporcional al brillo percibido de la distancia del rectángulo de la derecha. Esto sugiere que el conocimiento implícito o explícito de las personas y las tasas de sus proporciones en la ley de Arquímedes de las palancas, y quizá en otras leyes de la física, podrían potencialmente ser usadas para medir la fuerza subjetiva en una escala de proporción.

Palabras clave

Leyes físicas, psicofísica, ley de Arquímedes, teoría de integración de la información . 


\section{Para citar este artículo:}

Masin, S. C. (2016). The weight of light. Universitas Psychologica, 15 (3). http://dx.doi.o rg/10.11144/Javeriana.upsy15-3.twol

\section{The weight of light}

For a lever resting on a fulcrum with a weight $W_{1}$ on the left side at a distance $D_{1}$ from the fulcrum and a weight $W_{2}$ on the right side at a distance $D$ ${ }_{2}$ from the fulcrum, Archimedes' law states that the lever is horizontal when

$$
\frac{D_{1}}{D_{2}}=\frac{W_{2}}{W_{1}} .
$$

Functional measurement methodology yields evidence that people know this law correctly (Masin, Crivellaro, \& Varotto, 2014; Surber \& Gzesh, 1984; Wilkening \& Anderson, 1982). For example, given fixed values of $D_{2}$ and $W_{1}$, when people lift $W_{1}$ and $W_{2}$ they can predict values of $D_{1}$ for different values of $W_{2}$ which are consistent with Equation 1.

Equation 1 suggests comparison of ratios. Archimedes' law is also frequently expressed as $D_{1} \cdot W_{1}=D_{2} \cdot W_{2}$ which suggests comparison of products. It is undetermined which of these comparisons people use. When people apply their knowledge of Archimedes' law, they respond to ratios explicitly if they compare ratios or implicitly if they compare products.

Can the knowledge of Archimedes' law of the lever be used to measure subjective intensities? This question was explored long ago by Monroe (1925). "Weight of color" is the subjective impression of the amount of color of a surface (Alexander \& Shansky, 1976; Bullough, 1907; Pinkerton \& Humphrey, 1974). To measure this subjective impression, Monroe used two horizontally aligned disks of different colors joined by a line. Participants were instructed to imagine the line as a balance arm and to indicate the fulcrum of the arm on the line.
Monroe found that the fulcrum was displaced toward the color with larger relative "weight." He believed that "the judgment as to the place where an imaginary fulcrum would need to be placed on the line in order for the colors to appear balanced in weight would give a means of measuring the difference between the apparent weights of the colors" rather than of measuring "how much heavier one member of the pair of colors appears than the other" (Monroe, 1925, p. 192) (emphasis added). Monroe's belief that participants could not respond to ratios may have been unwarranted. He offered no explanation for his negative belief.

Using functional measurement methodology, the following study reexplored whether the knowledge of Archimedes' law of the lever can be used to measure subjective intensities. The study attempted to determine whether this law may be used to scale perceived brightness.

\section{Method}

\section{Participants}

Thirteen university students participated in the experiment for a payment.

\section{Stimuli}

Figure 1 illustrates the experimental configuration, a horizontal red line and an inverted yellow $\mathrm{T}$ with the top end of the inverted $\mathrm{T}$ touching the horizontal line's center. Participants were asked to interpret the horizontal line (hereafter called the "beam") as a thin beam and the inverted $\mathrm{T}$ as a base with a vertical stem holding the beam in horizontal equilibrium. 


\section{Figure 1}

The horizontal line represents a beam and the inverted $\mathrm{T}$ a base with a stem holding the beam. Two rectangles depict the stimuli. $D_{1}$ and $D$ ${ }_{2}$ denote the distances from the fulcrum and $L_{1}$ and $L_{2}$ the luminance of the left and right stimuli, respectively.

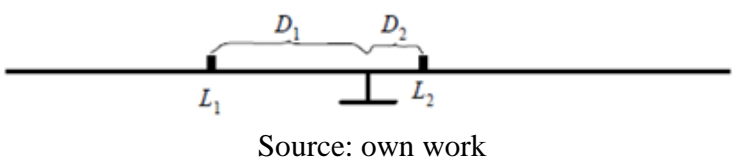

The stimuli were two uniformly achromatic rectangles attached above the beam, one on the left and one on the right of the fulcrum. Viewing distance was $1.3 \mathrm{~m}$. The stimuli were $5 \mathrm{~mm}$ wide and $8 \mathrm{~mm}$ high. The beam was $1 \mathrm{~m}$ long and the inverted $\mathrm{T}$ was 45 wide and $55 \mathrm{~mm}$ high. The width of all lines was $1 \mathrm{~mm}$. In a dark room, the beam and the inverted $\mathrm{T}$ were constantly displayed in the middle of a $1.1 \mathrm{~m}$ wide, $0.55 \mathrm{~m}$ high black area of the screen of a NEC PlasmaSync 50MP2 monitor controlled by a HP Compaq 6710 b computer.

Each trial started with the presentation of the stimuli with the left stimulus randomly positioned along the left half of the beam. The participants positioned the left stimulus on the beam using a computer mouse and, when this task was accomplished, they pressed a mouse button which caused the stimuli to disappear. The right stimulus was located at 11.5, 28, 44.5, 61, or $77.5 \mathrm{~mm}$ from the fulcrum and its luminance was $2,5,10,15,30$, or $50 \mathrm{~cd} / \mathrm{m}^{2}$.

\section{Procedure}

Before the experiment started, the participants were briefly explained Archimedes' law of the lever. An example referring to the case of a child and an adult on a seesaw emphasized the need for the child and adult to be at different distances from the fulcrum to keep the seesaw horizontal. No equation or number was mentioned in this explanation.

For each trial, participants were asked to consider that the light from each stimulus had a weight proportional to its intensity and that this weight could tilt the beam. Participants were instructed to set the position of the left stimulus on the beam such that the weight of the light emitted by this stimulus kept the beam horizontal given the weight of the light emitted by the right stimulus. After participants had accomplished this task they clicked on the mouse. This action caused the stimuli to disappear and caused the computer to record the distance of the left stimulus from the fulcrum.

The luminance and the distance from the fulcrum of the right stimulus were combined factorially. The entire series of these combinations was presented twice consecutively with combinations randomly ordered.

\section{Results}

\section{Figure 2}

Mean adjusted distance of left stimulus from the fulcrum $D_{1}(\mathrm{~mm})$ plotted against the distance of the right stimulus from the fulcrum $D_{2}(\mathrm{~mm})$ for each value of the luminance of the right stimulus $L_{2}\left(\mathrm{~cd} / \mathrm{m}^{2}\right)$
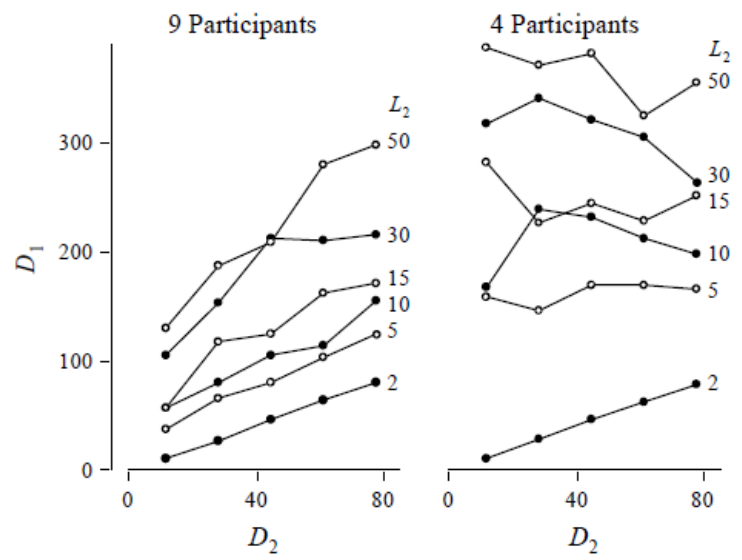

The left diagram shows the data for a group of 9 participants and the right diagram shows those for another group of 4 different participants. Source: own work

As illustrated in Figure 1, let $D_{1}$ denote the mean distance of the left stimulus from the fulcrum, $\mathrm{D}_{2}$ the distance of the right stimulus from the fulcrum, and $L_{1}$ and $L_{2}$ the respective stimulus luminance. Figure 2 shows $D_{1}$ plotted 
against $D_{2}$ separately for each value of $L_{2}$. Factorial curves diverged for 9 participants and were roughly parallel for the other 4 . The left and right diagrams show the results for these two groups of participants.

\section{Group of 9 participants}

The results for the group of 9 participants agree with the equation

$$
\frac{D_{1}}{D_{2}}=\frac{L_{2}}{L_{1}}
$$

showing that $D_{1}$ increased with $D_{2}$ for each fixed value of $L_{2}$ and increased with $L_{2}$ for each fixed value of $D_{2}$

\section{Figure 3}

Mean adjusted distance of left stimulus from the fulcrum $D_{1}(\mathrm{~mm})$ plotted against the distance of the right stimulus from the fulcrum $D_{2}(\mathrm{~mm})$ for each value of the luminance of the right stimulus $L_{2}\left(\mathrm{~cd} / \mathrm{m}^{2}\right)$

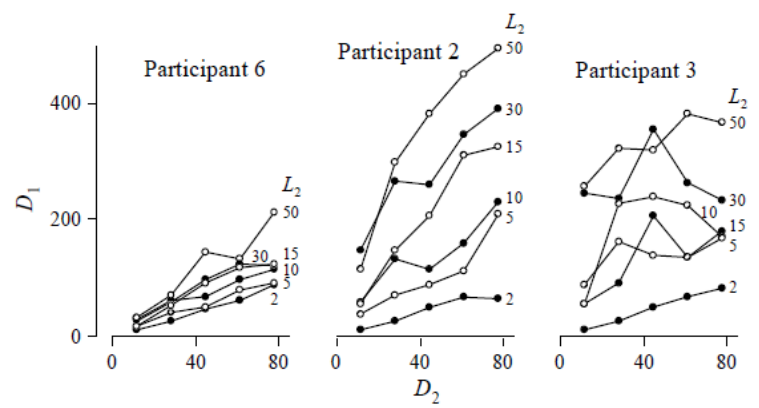

Each diagram shows the individual results for one of three participants (the participant's number denotes the order of participation in the experiment).

Source: own work

An analysis of variance showed that the effects of $L_{2}$ and $D_{2}$, and the interaction were significant, $F(5.40)=24.9, F(4.32)=38.8$, and $F(20.160)=2.9, p<0.001$, respectively. For $D_{2}$ the linear trend was significant and the quadratic, cubic, and quartic trends not significant, $F(1.8)$ $=60.4, p<0.001$, and $F(1.8)=3.97,0.40$, and 0.28 , respectively.
Figure 3 shows individual factorial curves for three participants. These individual results illustrate that each participant selected values for $D_{1}$ within an arbitrary range.

\section{Group of 4 participants}

The results for the group of 4 participants disagree with Equation 2 except when $L_{1}=L$ ${ }_{2}\left(2 \mathrm{~cd} / \mathrm{m}^{2}\right)$. Figure 2 shows that $D_{1}$ increased with $D_{2}$ in both diagrams when $L_{1}=L_{2}$. The group of 4 participants responded to $D_{2}$ when $L_{1}=L_{2}$ and only to $L_{2}$ when $L_{1}$ i $L_{2}$. These participants seemed unable to integrate $D_{2}$ and $L$ ${ }_{2}$ and responded either to $D_{2}$ or to $L_{2}$. Excluding the data for $L_{2}={ }_{2} \mathrm{~cd} / \mathrm{m}^{2}$, the effect of $L_{2}$ was significant, $F(5.15)=25.6, p<0.001$, and the effect of $\mathrm{D}_{2}$ and the interaction were not significant, $F(3.9)=0.6$, and $F(15.45)=1.0$, respectively.

It could be that the group of 4 participants had poor ability in handling cognitive variables (Halford, Wilson, \& Phillips, 1998) or that they did not properly understand the experimental task. In either case, some preliminary experience with an actual lever might help increase the number of participants using their knowledge of Archimedes' law.

\section{Discussion}

Let $\mathbf{i}_{1}, \mathbf{i}_{2} 2, \mathbf{i}_{1}$, and $\mathbf{i}_{2}$ denote the perceived distances and brightnesses corresponding to $D_{1}$, $D_{2}, L_{1}$, and $L_{2}$, respectively. In Figure 2, the results for the group of 9 participants show that factorial curves formed a set of diverging straight lines as predicted by Equation 2, supporting the hypothesis that

$$
\frac{\delta_{1}}{\delta_{2}}=\frac{\lambda_{2}}{\lambda_{1}}
$$

(Anderson, 1981, 1982). 
Figure 4

Ratio scale measure of brightness

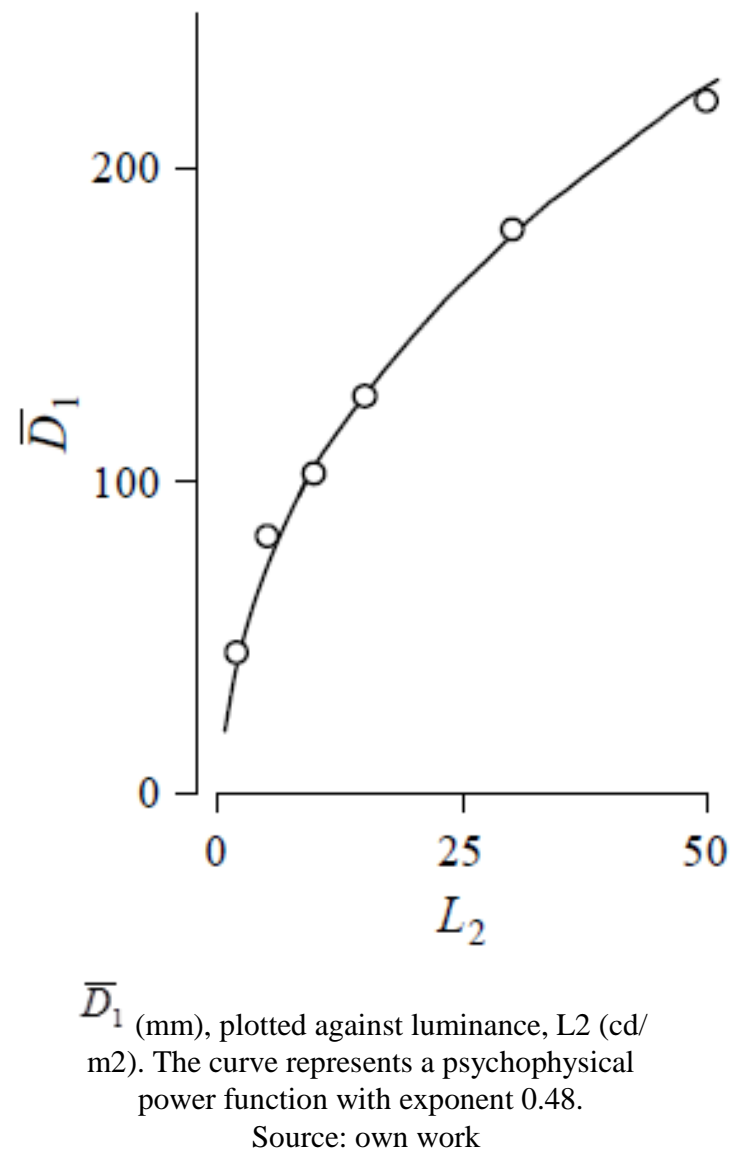

Empirical evidence shows that perceived and physical distance are related linearly, at least approximately (Masin, 2012; Masin \& Anali, 2011). That is, it shows that $D_{1}=k \cdot \mathbf{i} 1$ and $D_{2}=$ $k \cdot \mathbf{i}_{2}$ with $k$ constant. This evidence and Equation 3 imply that

$$
D_{1}=\frac{D_{2}}{\lambda_{1}} \cdot \lambda_{2}
$$

For each value of $3_{2}$, the mean of the values of $D_{1}$ obtained for each value of $D_{2}$ is

$$
\bar{D}_{1}=\frac{\bar{D}_{2}}{\lambda_{1}} \cdot \lambda_{2}
$$

with $\bar{D}_{1}$ the mean of values of $D_{2}$. Since $\lambda_{1}$ and $\bar{D}_{1}$ are constant, $\bar{D}_{1}$ is a measure of $\lambda_{2}$ on a ratio scale.

Assuming that the psychophysical law relating $\lambda_{2}$ to $L_{2}$ is a power function of the form

$$
\lambda_{2}=a \cdot L_{2}^{b}
$$

with $\alpha$ the proportionality constant and $\mathrm{b}$ the exponent, Equations 5 and 6 imply that

$$
\bar{D}_{1}=c \cdot L_{2}^{b}(7)
$$

with constant:

$$
c=\boldsymbol{q} \cdot \overline{\boldsymbol{I}_{2} / \lambda_{1}}
$$

In Figure 4, the left diagram shows $\bar{D}_{1}$ plotted against $L_{2}$. The curve represents a least-squares fit of Equation 7 with $c=34.7$ and $b=0.48$ with standard deviations of 3.9 and 0.14 , respectively.

These results are consistent with the general hypothesis that people's explicit or implicit knowledge of ratios and proportions in Archimedes' law, and perhaps in other physical laws, may be used to measure the intensity of any subjective experience on a ratio scale. That is, this hypothesis may apply to subjective sensory intensities (e.g., the intensity of attributes of sound or color) as well as to subjective nonsensory intensities (e.g., the intensity of attitudes or beliefs) and may possibly also allow the study of quantitative relationships between these different types of subjective intensities. The exploration of this general hypothesis might be a promising field of inquiry.

\section{Acknowledgement}

The author would like to thank D. Algom, N. H. Anderson, and an anonymous reviewer for providing useful feedback on drafts of this paper. 


\section{References}

Alexander, K. R., \& Shansky, M. S. (1976). Influence of hue, value, and chroma on the perceived heaviness of colors. Perception \& Psychophysics , 19, 72-74.

Anderson, N. H. (1981). Foundations of information integration theory. New York: Academic Press.

Anderson, N. H. (1982). Methods of information integration theory. New York: Academic Press.

Bullough, E. (1907). On the apparent heaviness of colors. British Journal of Psychology, 2 , 111-152.

Halford, G. S., Wilson, W. H., \& Phillips, S. (1998). Processing capacity defined by relational complexity: Implications for comparative, developmental, and cognitive psychology. Behavioral and Brain Sciences , 21, 803-831.

Masin, S. C. (2012). Fundamental measurement of perceived length and perceived area. International Journal of Psychological Studies , 4 (3), 23-33.

Masin, S. C., \& Anali, D. (2011). Simultaneous use of different mental standards in magnitude estimation of line length. In D. Algom, D. Zakay, E. Chajut, S. Shaki, Y. Mama, \& V. Shakuf (Eds.), Proceedings of the twenty-seventh annual meeting of the International Society for Psychophysics (pp. 233-238). Raanana, Israel: International Society for Psychophysics.

Masin, S. C., Crivellaro, F., \& Varotto, D. (2014). The intuitive physics of the equilibrium of the lever and of the hydraulic pressures: Implications for the teaching of elementary physics. Psicológica , 35, 441-461.

Monroe, M. (1925). The apparent weight of color and correlated phenomena. American Journal of Psychology, 26, 192-206.

Pinkerton, E., \& Humphrey, N. K. (1974). The apparent heaviness of colours. Nature, 250 , 164-165.
Surber, C. F., \& Gzesh, S. M. (1984). Reversible operations in the balance scale task. Journal of Experimental Child Psychology , 38, 254-274.

Wilkening, F., \& Anderson, N. H. (1982). Comparison of two rule-assessment methodologies for studying cognitive development and knowledge structure. Psychological Bulletin, 92, 215-237.

\section{Notes}

* Research article. 